\title{
LEITURAS PROFISSIONAIS DOCENTES E APROPRIAÇÃO DE SABERES ACADÊMICO-EDUCACIONAIS
}

\author{
FLAVIA MEDEIROS SARTI \\ Departamento de Educação do Instituto de Biociências da \\ Universidade Estadual Paulista - Campus Rio Claro \\ fmsarti@rc.unesp.br
}

BELMIRA OLIVEIRA BUENO

Faculdade de Educação da Universidade de São Paulo

bbueno@usp.br

\begin{abstract}
RESUMO
O artigo focaliza processos relacionados ao movimento atual de "universitarização" da docência, procurando caracterizar modos pelos quais professoras das quatro primeiras séries do ensino fundamental leram e se apropriaram de textos acadêmico-educacionais em um contexto de educação continuada. As análises apresentadas foram elaboradas no âmbito de uma investigação etnográfica, realizada em dois pólos do Programa de Educação Continuada - PEC - Formação Universitária (São Paulo). Observou-se que a atuação de diversos dispositivos em tais contextos, assim como nos textos lidos, favoreceu a instauração de um "novo padrão de leitura" entre as professoras. As posturas e os procedimentos por elas assumidos, por sua vez, sugeriram a existência de uma leitura profissional propriamente docente, caracterizada entre outros aspectos por uma racionalidade prática que possibilitava às professoras subverter a ordem dos discursos presente nos textos. A centralidade dos saberes e interesses práticos das docentes para a configuração de suas leituras de caráter profissional reafirma a importância da cultura pedagógica compartilhada no magistério como fonte de conhecimentos mais pertinentes para o ensino e como eixo da formação docente.

FORMAÇÃO DE PROFESSORES - PROFESSORES - LEITURA - ENSINO FUNDAMENTAL
\end{abstract}

\section{ABSTRACT}

TEACHERS' PROFESSIONAL READINGS AND APPROPRIATION OF ACADEMICEDUCATIONAL KNOWLEDGE. The article focus on processes related to the current movement towards teaching "universitarization", seeking to characterize the modes by which first to four grade teachers read academic-educational texts and got hold of them, within a continuing education context. An ethnographic approach was adopted and the data were collected in two poles of the Continuing Education Program - PEC - University Education (São Paulo, Brazil). It has been observed that the role of several mechanisms within such 
contexts, as well as the texts read, favoured the implementation of a "new reading pattern" among the teachers. On the other hand, the attitudes and procedures adopted by them suggested the existence of a professional reading peculiar to teachers, characterized, among other aspects, by a practical rationality which enabled teachers to subvert the order of the discourses in the texts. The centrality of the knowledge and practical interests of the teachers for the configuration of their professional readings reaffirm the importance of the pedagogical culture shared in the teaching profession both as a source of knowledge more appropriate for teaching and as the core for teacher education.

TEACHER EDUCATION - TEACHERS - READING - ELEMENTARY SCHOOL

O cenário educacional brasileiro tem apresentado nos últimos anos uma prodigiosa expansão no que se refere à formação em nível superior dos professores que atuam nas quatro primeiras séries do ensino fundamental. De acordo com dados oferecidos pelo Instituto Nacional de Estudos e Pesquisas Pedagógicas (Brasil, 2003), entre 1996 e 2002, houve, entre nós, um crescimento de 10\% no número de professores desse nível de ensino que possuem diploma superior, enquanto no período imediatamente anterior, entre 1991 e 1996, o aumento havia sido de pouco mais de $1 \%$.

Essa crescente universitarização do magistério das séries iniciais integra um movimento mais amplo de profissionalização e de revalorização social dos professores (Bourdoncle, 1997, 2000), que tem como pressuposto a intenção de racionalizar as práticas profissionais docentes, tornando-as mais "eficazes" pela assimilação de saberes pedagógicos de natureza científica e de posturas e valores geralmente associados a uma cultura de tipo acadêmica. Intensificamse, com isso, as relações estabelecidas entre professores desse nível de ensino e o ambiente acadêmico, o que concorre para diminuir, em vários sentidos, a separação que historicamente tem sido mantida entre essas instâncias.

Uma visão mais perspicaz acerca desse novo panorama da formação docente requer que se questione os modos pelos quais os professores se defrontam com as políticas voltadas para a sua formação e como se "apropriam dos objetos e valores que lhes são impostos e dados a consumir" (Bueno, 2003, p. 14). Apoiando-nos em Michel de Certeau (1994, p.4I), indagamos sobre as "maneiras de fazer" dos professores quando estes se reapropriam dos espaços formativos organizados por "técnicas de produção cultural". Trata-se de desvelar formas de submissão e também de rebeldia que se fazem presentes nas operações de "caça não autorizada" (p.38) pelas quais os consumidores - 
Leituras profissionais docentes...

no caso, os professores - se apropriam de determinados produtos culturais (Bueno, 2003, 2006).

Entende-se que a universitarização da docência das séries elementares impõe desafios importantes associados, entre outros aspectos, ao encontro de diferentes culturas profissionais aí envolvidas: de um lado, professores das séries iniciais e, de outro, pesquisadores acadêmicos; grupos no interior dos quais são partilhadas maneiras específicas de conceber o ensino, a aprendizagem, a escola, os alunos, a docência, entre outros aspectos relacionados à formação dos professores e ao seu papel profissional. Interessa, pois, conhecer melhor como esses dois grupos interagem no campo da formação docente, o que inclui identificar, entre outros fatores: o lugar que cada um deles assume nesse espaço, os recursos que empregam para fazer valer suas posições, bem como os embates e as disputas que, a partir daí, são estabelecidos entre eles. Cabem, ainda, esforços voltados para a identificação de caminhos que favoreçam a superação de possíveis impasses que então se apresentam.

Questões dessa natureza são aqui examinadas a partir de dados e análises inicialmente propostos no âmbito de uma investigação que focalizou processos relativos à circulação de discursos acadêmico-educacionais entre professores das quatro primeiras séries do ensino fundamental' (Sarti, 2005; Sarti, Bueno, 2006, 2006a). A pesquisa foi realizada sob uma abordagem etnográfica e teve como referencial empírico o PEC-Formação Universitária ${ }^{2}$. $O$ estudo procurou descrever e caracterizar modos pelos quais professoras ${ }^{3}$ das séries iniciais, então alunas no referido programa, leram e se apropriaram de textos acadêmico-educacionais que Ihes foram oferecidos naquele contexto. Os dados reunidos pela investigação ressaltaram especificidades associadas às

I. Estudo financiado pela Fundação de Amparo à Pesquisa do Estado de São Paulo - Fapesp.

2. Programa implementado pela Secretaria de Educação do Estado de São Paulo - SEE-SP - em parceria com a Universidade de São Paulo - USP -, a Pontifícia Universidade Católica de São Paulo - PUC-SP - e a Universidade Estadual Paulista - Unesp. Foi realizado entre julho de 2001 e dezembro de 2002 e, segundo dado divulgado pela SEE-SP, concedeu diploma de licenciatura plena a 6.233 professores que possuíam, até então, apenas a habilitação para o magistério em nível médio. Embora não tenha sido formalmente classificado na modalidade de educação a distância, apresentava características desse ensino, como o forte apoio de mídias interativas.

3. Como o universo focalizado pela pesquisa era composto quase exclusivamente por mulheres, optou-se pelo emprego dos termos no feminino. 
Flavia Medeiros Sarti e Belmira Oliveira Bueno

duas culturas profissionais envolvidas, evidenciando, inclusive, modos pelos quais cada uma delas tende a se aproximar de assuntos educacionais e a considerá-los.

\section{UNIVERSITARIZAÇÃO DO MAGISTÉRIO E LEITURAS ACADÊMICO- EDUCACIONAIS}

Ao pôr em marcha esse processo de universitarização da docência das séries elementares, o Brasil junta-se a outros países que, em diferentes momentos do século $X X$, buscaram operar mudanças desse tipo no status da formação de seus professores primários. Esse é o caso dos Estados Unidos, ainda na década de 30; do Canadá e da Inglaterra nos anos 60; da Austrália nos anos 70; do México na década de 80; da França nos anos 90; entre outros exemplos (Bourdoncle, 1997, 2000). No contexto brasileiro, o movimento foi impulsionado, sobretudo, pela Lei de Diretrizes e Bases da Educação Nacional - LDB n. 9.334 que, em 1996, preconizou a habilitação superior para os professores desse nível de ensino4.

Tais diretrizes legais foram recebidas com inquietação pelos professores em exercício que, à época, não possuíam diploma de ensino superior e que, conseqüentemente, sentiram-se ameaçados pela possibilidade de perderem seus direitos de exercício profissional. Tendo em vista obter a certificação requerida e, assim, assegurar a estabilidade profissional, muitos deles ingressaram em cursos de Pedagogia ou Normal Superior, ambos voltados para a formação docente. Além dessas ações individuais assumidas por muitos professores, o cumprimento das disposições apontadas pela referida LDB motivou vários estados e municípios brasileiros a adotarem estratégias específicas para a formação de seus quadros docentes em nível superior. Muitos deles buscaram firmar parcerias com universidades para a criação de programas especiais de formação que possibilitassem diplomar, de uma só vez, um grande

4. Na década de 70, assistimos no Estado de São Paulo a um movimento precursor desse processo, quando, por exigência da Lei n. 5692/7I, um grande contingente de profissionais do ensino teve de correr em busca da licenciatura em Pedagogia, sem a qual não poderia exercer cargos de direção e outras funções administrativas da carreira do magistério. A este respeito, ver Vieira (2002) e Santos (2003). 
número de professores; isso sob condições específicas caracterizadas, sobretudo, por limitações de tempo e de espaço ${ }^{5}$.

Nessa direção, milhares de professores em exercício passaram, em todo o país, a integrar os quadros discentes do ensino superior (ES), quer seja em cursos regulares de licenciatura ou em programas especiais de formação continuada docente. É preciso admitir que para muitos desses professores a (sobre)vivência no ES é acompanhada por desafios diversos, já que pressupõe a realização de atividades que lhes são pouco familiares, como a leitura de textos produzidos no ambiente universitário ou a elaboração de trabalhos de natureza acadêmica, bem como exige o contato com modos alternativos de abordar temas educacionais e pedagógicos.

Para as instituições de ES as dificuldades não parecem ser menores. Além das já mencionadas limitações de tempo e de espaço que se impõem para sua atuação na formação dos professores (o que tem sido enfrentado, na maior parte dos casos, pelo emprego extensivo de mídias interativas), uma tal empreitada requer que se ultrapasse os objetivos comumente presentes no modelo universitário convencional, baseado sobretudo na teorização de questões educacionais. Insuficiências desse modelo formativo mostram-se flagrantes, especialmente no caso do atendimento oferecido a professores mais experientes, cujos saberes e práticas acham-se mais firmemente ancorados na cultura da escola e do magistério, da qual faz parte um habitus ${ }^{6}$ profissional específico

5. Além do PEC-Formação Universitária, é possível citar vários exemplos: o Curso Normal Superior realizado pela parceria entre a Universidade Estadual de Ponta Grossa, a Universidade Eletrônica do Paraná e a Secretaria Estadual de Ciência, Tecnologia e Ensino Superior do Paraná; o Projeto Veredas, implementado pela Secretaria Estadual de Educação de Minas Gerais; o PEC-Municípios, resultado de parceria entre a Fundação para o Desenvolvimento da Educação, diversos municípios paulistas, a USP e a PUC-SP (a parceria foi intermediada pela União dos Dirigentes Municipais-SP).

6. O conceito de habitus é definido por Pierre Bourdieu (1983, p.94) como: um "sistema de disposições adquiridas pela aprendizagem implícita ou explícita que funciona como um sistema de esquemas geradores [de práticas]". Para Bourdieu, as relações que os indivíduos estabelecem com o meio social são intermediadas pelo habitus aprendido em seus respectivos grupos de pertença. A esse respeito, Norbert Elias, citado por Chartier (1988), adverte que tais processos ocorrem em meio às relações de "interdependência" e de "reciprocidade" que são estabelecidas entre os seres sociais o que, entre outros fatores, acarreta a própria reelaboração do habitus em questão. 
(Perrenoud, 1993) - o habitus pedagógico - que estrutura a prática docente e é por ela reestruturado (Bueno, 1996).

Vê-se, pois, que o cenário ora constituído em torno da formação docente é fonte de novas experiências para os diferentes grupos profissionais envolvidos que, com base em saberes objetivos, habitus e referências institucionais que Ihes são próprios, embora não exclusivos, interagem na composição do campo educacional. Esse tema será explorado mais detidamente a seguir.

\section{POR UMA LEITURA PROFISSIONAL DOCENTE}

As atividades de campo da pesquisa cujos dados são aqui retomados foram realizadas ao longo de 15 meses no interior de duas turmas do PECFormação Universitária. Os ambientes observados apresentavam diferenças significativas no que se refere aos hábitos e às experiências prévias de leitura das alunas-professoras que os compunham. Enquanto as professoras reunidas no Pólo $I^{7}$ enfrentavam diversas dificuldades no contato com textos educacionais de natureza acadêmica (falta de acesso, desconhecimento dos processos de produção e divulgação, insuficiência conceitual, estranhamento em relação ao léxico empregado etc.), as docentes reunidas no Pólo II apresentavam razoável desenvoltura na leitura dos mesmos textos.

No entanto, essas discrepâncias quanto aos hábitos e às experiências de leitura das professoras não anularam certas similaridades que as uniam no tocante aos procedimentos de leitura dos textos acadêmico-educacionais. Nesse sentido, foram identificados indícios de um tipo de comunidade social de interpretação ${ }^{8}$ que agregava as leituras profissionais do grupo de professoras em torno de uma mesma perspectiva prática, orientada por uma mesma lógica da ação. Observou-se, por exemplo, que as leituras dos textos acadêmico-

7. As denominações Pólo I e Pólo |l são utilizadas no estudo para designar as duas localidades focalizadas, mas não correspondem a nomenclaturas empregadas no PEC-Formação Universitária.

8. O conceito de "comunidade de interpretação" foi formulado por Fish (1982) na esfera da crítica literária. Neste trabalho a idéia de comunidade de interpretação dos textos foi considerada em um sentido amplo, que compreende aspectos sociais presentes na leitura, entre os quais: o lugar social ocupado pelos sujeitos, o contexto no qual as leituras são realizadas e as representações implicadas. 
educacionais caracterizavam-se pela presença marcante da oralidade no exame e discussão de assuntos relacionados à vida cotidiana escolar.

Com isso, tais leituras profissionais assumiam feições específicas, bastante próximas da docência diária. Recorrendo, então, a certas "estratégias de oralidade letrada" (Kleiman, 200 I, p.59), as professoras costumavam evocar situações práticas durante a leitura dos textos, de modo a "traduzir" ou exemplificar o que "o autor queria dizer". Em algumas situações, no entanto, eram as idéias dos autores que agiam no sentido de justificar, problematizar ou contestar situações práticas que as professoras pretendiam abordar nas discussões. Havia casos, ainda, em que a recorrência a exemplos práticos objetivava a contestação de idéias que elas consideravam terem sido propostas pelo autor do texto lido. Os textos eram assim assumidos pelas professoras como "ataIhos" para a análise de suas experiências docentes no contexto escolar; fazendo emergir suas percepções e avaliações acerca dos impactos que os temas propostos no texto representavam para a vida diária na escola e para o trabaIho docente.

Essa postura indicou que tais professoras empregavam um tipo de "tática de consumo" (Certeau, 1994, p.47) que implicava assumir temporariamente o lugar dos autores dos textos lidos e, valendo-se furtivamente dessa posição de poder, faziam imperar seus modos específicos de ler e de se apropriar dos discursos. Com isso, transformavam as leituras ali realizadas em "ocasiões" para a reflexão e/ou questionamento de fatores que se impunham a sua atividade e condição profissional. Elas se valiam então do limitado espaço de liberdade do qual dispunham para subverter a "ordem dos discursos" (Chartier, 1999) proferidos, tornando-os mais próximos de seus interesses e necessidades de trabalho. Por meio de tal engenhosidade, introduziam o seu próprio mundo - o mundo docente - no lugar daquele proposto pelo autor do texto.

Os textos que circulavam no curso costumavam ser avaliados pelas professoras pelo grau de interlocução com o cotidiano escolar que eles lhes possibilitavam. Elas pareciam desejosas de encontrar imagens de si mesmas, de seus alunos e dos problemas que enfrentavam na escola retratadas pelos autores e, por isso, se queixavam dos textos com os quais não conseguiam "dialogar" sobre suas práticas profissionais, tendo em vista suas preocupações, interesses e saberes. Com esse posicionamento, as professoras pareciam reafirmar o valor de seus próprios saberes e práticas profissionais, recursos dos quais dis- 
punham para se apropriar de textos educacionais, bem como do espaço e de práticas acadêmicas.

As professoras analisavam os discursos apresentados nos textos por uma ótica particular, cuja centralidade residia em questões bastante pontuais presentes no cenário escolar, o que incluía, entre outros fatores: o tempo e o espaço da aprendizagem e do ensino, os objetivos da docência, além das relações estabelecidas entre os sujeitos. Para elas, a discussão dos temas educacionais exigia que se contemplassem todas as variáveis inscritas na efetivação das práticas pedagógicas com os alunos. As relações que estabeleciam com os textos convertiam-se, desse modo, em leituras de trabalho, percebidas pelas professoras com base em seu valor de uso (Bourdieu, 1996), para o atendimento das necessidades e a resolução de problemas que elas enfrentavam no exercício de seu ofício.

A forma pela qual as professoras apropriavam-se dos discursos acadêmico-educacionais que circulavam no programa mostrava-se ancorada na cultura profissional docente, vinculada ao trabalho cotidiano escolar e, portanto, à capacidade de tomar decisões diante dos eventos e das urgências impostas à vida ordinária institucional. Essa "arte prática", nos termos empregados por Israel Scheffler (1974), ou "arte do fazer", segundo definição de Michel de Certeau (1994), está ligada a saberes que, em sua maior parte, são invisíveis e desconhecidos. Assim, ao se aproximarem de textos educacionais produzidos no ambiente acadêmico, as professoras valiam-se de modos de ler que AnneMarie Chartier (1999) já havia identificado como sendo ancorados em saberes e interesses de ordem prática. No caso das professoras do estudo, entende-se que a centralidade assumida por tais critérios práticos era ainda mais acentuada em razão do seu perfil profissional: docentes com mais de dez anos de experiência no magistério e, portanto, com maior liberdade para tomar decisões baseadas nesses critérios.

Pressupõe-se que essa lógica, vinculada a uma perspectiva prática, era a principal responsável pela avaliação que as professoras faziam das leituras profissionais realizadas no programa. Em razão desses critérios de natureza específica, elas "escolhiam" os textos, conceitos e idéias que Ihes pareciam mais interessantes, quer seja do ponto de sua utilidade para o exercício da docência - seu valor de uso - ou do valor simbólico a eles agregado, fonte de legitimidade para suas práticas, posicionamentos e discursos. Dado o caráter for- 
mativo e escolar do ambiente investigado, tais "escolhas" não implicavam necessariamente a seleção dos textos que seriam lidos, mas sim a eleição das leituras que "valiam a pena" e que, portanto, seriam objeto de maior atenção e empenho durante as sessões de leituras. Todos os textos propostos pelo programa deveriam ser lidos pelas professoras, independentemente do interesse que lhes despertavam. Mas, por parte das professoras daquelas duas turmas, especial atenção era dispensada se as possibilidades de aproximá-las de temas considerados mais centrais e urgentes fossem maiores. Essa atenção parecia ainda mais expressiva se os textos e autores lidos Ihes parecessem associados a alguma possibilidade de "uso mais imediato" no contexto profissional, quer fosse para a resolução direta de problemas junto aos alunos ou para legitimar práticas e posicionamentos profissionais que elas já vinham assumindo.

Essas considerações sobre o caráter específico das leituras profissionais das professoras motivaram esforços para a explicitação dos critérios que presidiam suas "escolhas" e o grau de investimento pessoal (de energia e de tempo, especialmente) aí presentes. Com base nas análises ensaiadas a esse respeito, elaborou-se um esboço sobre a "temporalidade dos usos" nas leituras profissionais docentes, por meio do qual pretendeu-se evidenciar fatores que se entrecruzavam para as "escolhas" das professoras, no que diz respeito ao tratamento dos textos acadêmico-educacionais que lhes chegavam às mãos. Os dados reunidos foram analisados, nesse sentido, sob ótica apontada por Raymond Boudon (1977, 1999), que ressalta a centralidade assumida pelos interesses dos sujeitos no desencadeamento de suas ações, para o qual competem, ainda, suas intenções de elevar os benefícios então alcançados e de reduzir os investimentos que devem ser empregados.

Sob tal perspectiva, entende-se que as professoras "escolhiam" suas leituras em função do valor (de uso ou simbólico) que Ihes atribuíam para o atendimento de seus interesses profissionais. De acordo com os dados reunidos, elas esperavam que os textos Ihes possibilitassem, entre outras ações: debater especificidades do trabalho que realizavam na escola; reunir informações para cumprir as atividades ligadas ao programa (provas, monografia final, vivências educativas, oficinas culturais etc.); justificar teoricamente suas ações profissionais; informar seus questionamentos sobre atitudes tomadas pela direção da escola; ter contato com autor/es "legítimo(s)" no meio educacional, ou mesmo, incrementar sua formação para rivalizar com colegas que freqüentavam 
cursos regulares de graduação, e que costumavam menosprezar o PEC, identificado por elas como um curso a distância.

O valor associado à leitura de cada texto era, ainda, balizado pelas professoras em função da maximização dos benefícios esperados. Os critérios envolvidos em suas leituras articulavam-se de diferentes formas em cada situação, conferindo certa mobilidade e diversidade para as "escolhas" realizadas, que tinham como eixo central os interesses de professoras experientes em seu ofício. Em todos os casos, porém, os textos mais valorizados por elas eram aqueles que thes possibilitavam maiores chances de verem a si mesmas, de algum modo, neles "refletidas" (seu ambiente de trabalho, seus alunos, suas preocupações, urgências, frustrações etc.).

Indícios a esse respeito puderam ser percebidos em diversas ocasiões ao longo das atividades de campo. Assim foi, por exemplo, durante a leitura de um livro (Elias, 2000) que aborda os pressupostos construtivistas relacionados à alfabetização. De acordo com as orientações oferecidas na apostila do programa, cada grupo deveria ler um dos capítulos do livro em questão, realizar uma síntese e apresentar as "idéias centrais do autor" para o restante da turma, por meio de um pôster. Este deveria abordar: a concepção de alfabetização, de leitura e de escrita assumida pela autora, além de "outros aspectos considerados relevantes para compreender o processo de alfabetização" (São Paulo, 200 I, p.723).

Vê-se, pois, que a aproximação com o texto, tal como sugerida na apostila, orientava-se pela busca do seu sentido literal e pela exploração das idéias nele apresentadas. Às professoras caberia o papel de identificar as concepções propostas pela autora do texto e comunicá-las para o restante da turma. Tendo em vista a realização daquela atividade, as professoras reuniram-se em grupos de aproximadamente oito integrantes, utilizando diferentes espaços do prédio (salas ociosas, pátio etc.). Como a turma foi dividida em vários grupos, nenhum deles contou com um auxílio mais direto por parte da tutora da turma que, no entanto, de quando em quando aproximava-se das professoras perguntando se havia alguma dificuldade e se a atividade estava sendo realizada.

As atividades de leitura de um dos grupos foram observadas mais demoradamente 9 . Durante a leitura do texto, aquele grupo pareceu enfrentar difi-

9. Registro de observação realizada em uma sala de aula ociosa do pólo, em 24/04/2002. 
culdades para compreender alguns termos e expressões e, também, certos conceitos relacionados à teoria construtivista. Em alguns momentos, as professoras recorreram à pesquisadora para solucionar tais dúvidas e, assim, poder compreender "o que a autora do livro queria dizer". Não obstante essa postura um tanto titubeante em relação ao significado de palavras do texto, as professoras mostraram-se bastante à vontade para propor exemplos práticos que, para elas, ilustrariam ou mesmo "traduziriam" cada trecho lido. Assim como no caso das leituras coletivas, realizadas com toda a turma, as professoras segmentaram o texto em blocos de idéias, que eram analisadas e discutidas. Quando decidiam interromper a leitura (realizada em voz alta por uma delas), passavam a falar sobre como seus alunos escreviam ou liam ("comendo letras", por exemplo), as dificuldades que enfrentavam e as maneiras pelas quais elas próprias vinham lidando com tais fatores. A "tradução" das idéias da autora por meio de exemplos pareceu conferir maior dinamismo ao grupo e mesmo as professoras que até então permaneciam quietas - apenas seguindo a leitura empreendida pelas demais colegas - mostraram-se, a partir dali, mais dispostas a participar do debate. Ao invés de explorar mais detidamente o texto e de parafraseá-lo - como a tutora costumava fazer durante as leituras realizadas coletivamente na turma - elas associavam-lhe casos exemplares que ensejavam longas discussões sobre o contexto de ensino em que as professoras vinham realizando seu trabalho nas escolas.

As professoras passaram a falar, então, sobre o "fracasso" que associavam à implementação de propostas pedagógicas ligadas ao construtivismo. Sobre esse aspecto, uma das professoras do grupo desabafou: "É isso que me dá um nó no estômago!" Ela se dizia aflita com relação ao futuro de seus alunos, que não vinham se mostrando capazes de ler ou escrever de modo fluente. Com o objetivo de justificar tais apreensões, tomou o exemplo das próprias colegas do PEC-Formação Universitária que, segundo ela, haviam cursado a escola básica em uma época em que "os alunos tinham de aprender" e que, mesmo assim, enfrentavam sérias dificuldades para ler textos acadêmicos como os propostos no programa. Para ela, seus atuais alunos terão dificuldades ainda mais sérias para ler e escrever na fase adulta, já que as reformas pedagógicas que tomaram por mote os conceitos construtivistas não alcançaram o objetivo de "formar alunos mais criativos" (segundo ela, uma meta prevista) e acabaram por favorecer a formação de "uma legião de alunos copistas" que 
"passam pela escola sem aprender", por "não terem de aprender", uma vez que não serão reprovados. As demais professoras do grupo pareceram concordar com essas observações. A discussão passou a versar, então, sobre os prejuízos trazidos pela progressão continuada no que se refere à falta de disciplina dos alunos para a realização das atividades escolares, já que eles não se vêem ameaçados pela possibilidade de repetência.

Objetivando cumprir a atividade proposta, havia momentos em que as professoras tentavam se ater mais diretamente ao texto, integrando suas informações e as resumindo. Isso ocorreu, por exemplo, quando outra docente do grupo ressaltou que o texto estudado baseava-se em idéias de Emília Ferreiro, segundo as quais é preciso "maturidade, tempo e paciência para a alfabetização". A sistematização proposta por essa professora provocou reação imediata por parte de uma das colegas, que retomou o eixo das experiências pessoais e profissionais: "Isso é o que irrita. Você pega um aluno que nunca viu nada sobre escrita e te dizem: 'tempo, maturidade e paciência'. Pensam que se deixarmos esse aluno ali ele vai aprender!".

Outras professoras complementaram essa fala, destacando as dificuldades de aprendizagem enfrentadas por alunos que vivem em condições adversas (que residem em locais violentos, não contam com a presença do pai ou da mãe etc.) e que revelam atitudes de apatia, insegurança ou rebeldia. A discussão seguiu por alguns minutos, afastando-se da temática da alfabetização, da atividade proposta na apostila e das orientações da tutora. $\bigcirc$ grupo teceu então considerações sobre seu próprio comportamento, ou seja, sobre o fato de não se limitar a cumprir a atividade proposta:

P4: Mas o aluno não tem de ser crítico? (Todas riram.)

P5: (apontando para o livro que permanecia aberto sobre a mesa): Ler o que está escrito é uma coisa... o que está escrito é diferente da realidade!

$\mathrm{Pl}$ : Em boca fechada não entra mosca!

Novos risos por parte das professoras que se entreolharam e voltaram à exploração do texto, com vistas à composição do pôster solicitado na atividade. Passaram, então, a eleger os trechos do texto que deveriam constar do pôster; o que era anotado em uma folha por uma delas (PI). Em virtude do 
Leituras profissionais docentes...

pouco tempo que restava para a finalização da atividade, elas pareciam agora apressadas e aflitas. A partir daquele momento, a atividade de leitura e síntese do texto foi interrompida somente uma única vez, quando uma das professoras destacou um trecho do texto que lhe chamou especial atenção. Nele, Emília Ferreiro afirmava que "as crianças são facilmente alfabetizadas".

P3: Para ela é fácil alfabetizar!

PI: Vai ver que ela fez como aquele outro... o Rousseau, que alfabetizou somente os próprios filhos!

P6: Alfabetizar uma classe de 10 ou 15 alunos é mesmo fácil. Quero ver alfabetizar 35 como a gente!

episódio relatado parece exemplar no que se refere ao modo pelo qual as professoras focalizadas no programa realizavam as leituras requeridas, pautando-as em suas experiências profissionais docentes. Embora o texto em questão se limitasse a apresentar as etapas presentes no processo de alfabetização segundo as teorias construtivistas, a leitura realizada pelas professoras orientou-se inicialmente pela busca de exemplos que pudessem, de um lado, Ihes traduzir as etapas descritas e, de outro, confirmar, ou não, a pertinência para o cenário escolar das idéias apresentadas pela autora. A partir de tal procedimento, a discussão levada a efeito pelas professoras assumiu um caráter cada vez mais autônomo com relação ao texto, desvinculando-se de certo modo da temática mais direta nele proposta (as etapas da alfabetização). Nesse sentido, as professoras pareceram abdicar de construir uma compreensão mais detida do texto lido, tomando-o como um "atalho" para a análise de suas experiências docentes no contexto escolar; o que fez emergir os modos como elas percebiam e avaliavam o impacto que o tema proposto no texto vinha assumindo para a vida diária na escola e para o trabalho docente.

As professoras estabeleceram uma aproximação com aquele texto, em certos aspectos, distante do tipo de leitura sugerida na apostila do programa e enfatizada pela tutora da turma. Ao invés de, como indicado, buscarem o sentido literal das afirmações e de explorá-lo em direção a uma compreensão de tipo inferencial, as professoras priorizaram o exame das percepções que elas próprias 
compartilhavam sobre o ensino e a escola. Elas pareciam interessadas, sobretudo, em dividir suas impressões sobre o cenário vivenciado nas escolas em que lecionavam e, também, seus conflitos e dúvidas quanto ao modo pelo qual deveriam gerir as dificuldades que aí encontravam. Buscavam imagens sobre a escola que pareciam ultrapassar aquilo que era oferecido pelo texto.

Práticas de leitura como essa, repetidamente assumidas pelas professoras observadas, desviavam-se, em vários aspectos, do que costuma ser esperado em contextos de formação. Ao invés de se concentrarem na aprendizagem de valores, procedimentos e posturas próprias ao ambiente acadêmico (para o qual o programa atuava como uma "porta de entrada"), aquelas professoras traziam consigo seus próprios modos de ler e de se aproximar de temas educacionais. Com isso, subvertiam a ordem dos discursos acadêmicos presentes nos textos lidos, ao infiltrarem neles um tipo de racionalidade prática que lhes era inicialmente estrangeira.

\section{Racionalidade prática no reino das práticas discursivas}

Diferente do que ocorre entre os professores que, como dito, costumam aproximar-se de assuntos educacionais a partir de uma perspectiva caracteristicamente pragmática, a cultura partilhada em ambientes de tipo acadêmico baseia-se em uma racionalidade discursiva. Nela, os textos e seus autores adquirem legitimidade social suficiente para nomear, descrever e explicar teoricamente fenômenos relacionados ao ensino, à aprendizagem, ao trabalho docente e à instituição escolar. No seio dessa cultura profissional acadêmica, alguns fatores assumem destaque, entre os quais: a proximidade com disciplinas científicas de diferentes áreas e a produção e divulgação de saberes, prioritariamente, embora não exclusivamente, por meio da escrita, o que implica modos específicos de comunicação e de relação entre os grupos.

Nesse contexto, os discursos são avaliados em razão de sua "veracidade", a partir da autoridade e da legitimidade que alcançam para descrever o que, então, passa a ser assumido como a "realidade". Por meio desses procedimentos, os discursos "transformam o mundo em livro, colocam na confusão caótica dos acontecimentos e dos fenômenos a maravilhosa legibilidade da ordem do discurso, legibilidade construída, arbitrária, imposta e desejada" (Chartier, 2003, p. 13, tradução nossa). 
Leituras profissionais docentes...

No caso específico focalizado nesta pesquisa, o contato com práticas e valores ligados ao ambiente acadêmico constituía uma fonte de conflitos para as docentes, que se viam constantemente questionadas durante as provas, os trabalhos e as discussões nas videoconferências, sobre a veracidade dos saberes pedagógicos apresentados nos textos - sobre o que, elas geralmente não faziam oposição. Mas o que de fato Ihes interessava era discutir sobre a pertinência que esses mesmos saberes adquiriam para a instituição escolar em que lecionavam. Agradava-Ihes compreender melhor os conceitos presentes em propostas pedagógicas com as quais, muitas vezes, conviviam nas escolas (e que assumiam, com isso, certo valor simbólico). No entanto, isso não bastava para que se sentissem mais preparadas para os desafios enfrentados diariamente no exercício do magistério.

Discrepâncias dessa ordem entre a perspectiva acadêmica e a docente também se impunham como desafios para os profissionais envolvidos na implementação do programa, que assumiam, como parte de sua missão, a instauração, entre os professores - alunos do programa -, de hábitos, procedimentos e valores mais próximos à cultura acadêmica. Nesse sentido, as leituras propostas e efetivadas no ambiente do PEC tinham um duplo objetivo: revestiam-se de um caráter profissional, visando à divulgação de saberes educacionais de natureza acadêmica entre os professores, ao mesmo tempo em que assumiam um aspecto marcadamente formativo, tendo em vista a instauração de um "modo acadêmico" de ler os textos, orientado, sobretudo, por procedimentos de capitalização das informações.

A instauração desse "novo" modo de ler entre os professores contava com a atuação de alguns dispositivos ${ }^{10}$, entre os quais se destacam dois: os protocolos de leitura contidos nas apostilas do programa, que visavam orientar e conformar as leituras dos professores; e a atuação dos tutores das turmas, algo observado especialmente no Pólo I, onde a relação que a tutora estabelecia com os textos e seus gestos de leitura eram percebidos pelas próprias professoras como um modelo a ser aprendido. Por meio desses esforços formativos, objetivava-se que os professores alcançassem um modo con-

10. Se entendidos sob a perspectiva apontada por Foucault (1994), os "dispositivos" constituem estratégias de controle - explícitas ou sutis - que oferecem suporte a certos tipos de saberes e, ao mesmo tempo, são sustentadas por eles. 
siderado mais legítimo e, portanto, mais valioso do ponto de vista simbólico, de ler e de se apropriar dos textos educacionais no ambiente acadêmico.

De fato, observou-se que a leitura intensiva, exaustiva e pessoal - e, portanto, não coletiva e oralizada, como as professoras preferiam até então - se impunha a elas cada vez mais fortemente como o modelo legítimo de contato com os textos educacionais. Com isso, as docentes dos dois pólos mostravam-se cada vez mais críticas quanto aos hábitos de leitura que diziam ser partilhados entre seus pares e, também, quanto às próprias possibilidades de leitura fora do ambiente do programa. A avaliação que elas faziam a esse respeito era crescentemente influenciada por padrões acadêmicos que lhes apontavam um ideal de professor-leitor bastante exigente e, em muitos aspectos, distante da imagem que faziam de si mesmas e de suas condições objetivas de leitura.

Configurava-se, assim, uma situação de violência simbólica que, segundo Bourdieu (1996, 1998), caracteriza-se pela adesão por parte dos "dominados" ao ponto de vista dos "dominantes" (e, portanto, à situação de dominação) em meio aos embates estabelecidos em um determinado campo. Os primeiros passam a enxergar a si próprios pela perspectiva dos segundos, instituindo-se, a partir daí, uma "violência suave e freqüentemente invisível" (1998, p.4I).

A adesão aos modelos de leitura mais valorizados no PEC impedia que as professoras atribuíssem maior valor às leituras "superficiais" que costumavam realizar devido à falta de condições mais favoráveis. Assumir essas suas leituras - efetivadas muitas vezes na urgência, na desordem e na incerteza de ter memorizado e compreendido as informações - como aceitáveis ou como uma "bricolagem" imposta pela necessidade, colocaria em questão suas próprias representações sobre a legitimidade universitária. Elas acreditavam que uma formação profissional em nível superior decerto requereria a aprendizagem de novas posturas, valores e práticas.

Assim, se de um lado essas docentes transitavam pelas leituras indicadas no programa sob a ótica prática que caracteriza sua cultura profissional de pertença, apropriando-se dos textos por meio de táticas que os faziam "dialogar" com seus interesses e necessidades mais prementes, de outro, elas incorporavam novos procedimentos e padrões de leitura profissional que iam ao encontro de sua formação como "novas leitoras" de textos acadêmico-educacionais. As práticas, os valores e as posturas de leitura profissional que então emergiam eram produzidas por relações dialeticamente estabelecidas entre os 
Leituras profissionais docentes...

dispositivos de coerção empregados no programa e as táticas das quais as professoras se valiam no contato com os textos.

A situação resultante de tais embates parecia constituir fonte de sentimentos controversos para as professoras. Ainda que se orgulhassem de seus novos hábitos e práticas de leitura profissional (mais próximos ao modelo acadêmico) e os reconhecessem como caminhos para o estabelecimento de relações mais "valiosas" com a docência, elas se ressentiam da expropriação de seus próprios saberes e práticas profissionais. A racionalidade discursiva que fundamentava as relações a serem estabelecidas com os textos educacionais naquele ambiente requeria, por vezes, que as professoras se afastassem de suas preocupações mais imediatas concernentes ao ensino e passassem a considerar a centralidade de novos objetivos e procedimentos para a atuação docente, tais como: a pesquisa sobre o próprio ambiente de trabalho, com a identificação de indicativos estatísticos e a perspectiva dos diversos grupos da comunidade escolar; o exame teoricamente subsidiado da aprendizagem de seus alunos; a adoção de uma postura mais reflexiva diante da prática docente; e a busca de uma coerência teórica em suas ações. Realizando atividades desse tipo, as professoras mostravam-se satisfeitas por ter mais informações sobre o ensino, mas sentiam falta de discussões mais centradas nos saberes para o ensino.

\section{ENTRE A SECUNDARIZAÇÃO E A “REPROBLEMATIZAÇÃO” DOS SABERES EDUCACIONAIS}

Esse cenário de desencontros entre as duas culturas profissionais focalizadas pela pesquisa sugere desafios para os propósitos universitários relacionados à formação profissional docente. Isso porque a centralidade que parece ser assumida pelos interesses práticos dos professores em suas leituras profissionais aponta, como dito antes, para a existência de limites quanto ao tipo de formação que a universidade tem-Ihes proposto, cuja meta central costuma ser o tratamento teórico de questões educacionais.

Para as professoras que participaram da pesquisa, as formulações teóricas só pareciam adquirir sentido se constituíssem atalhos para o tratamento de questões de ordem prática que se Ihes apresentavam na docência cotidiana, o que reafirma os limites do modelo universitário convencional para a formação de professores experientes, cujos saberes e práticas estão fortemente arraigados à cultura da escola e do magistério. 
$\bigcirc$ atendimento às necessidades de formação profissional docente requer centralidade para a cultura pedagógica, que excede as teorias sobre o ensino, uma vez que ela é "produzida e partilhada socialmente pelos professores". Assim entendida, a cultura profissional docente não se restringe ao que as teorias educacionais informam sobre o ensino, mas tem por base saberes mais específicos que são mobilizados para o ensino e também saberes que adquirem sentido durante o ensino. Ancorados em uma perspectiva prática, esses saberes integram um "habitus pedagógico" e não são, por isso, decodificados em linguagem teórica. Tampouco podem ser ensinados, já que se fundamentam principalmente em ações passadas (Bueno, 1996, p. 127).

A importância dos saberes práticos para a docência tem sido divulgada no campo educacional já há algum tempo. Todavia, as políticas educacionais em curso para a formação de professores continuam a tomar por base uma concepção de profissão fundada na primazia dos saberes abstratos, que são organizados de modo a assumir uma sofisticação que os torna inacessíveis ao público mais geral (Bourdoncle, 2000). Esse modelo de profissionalização baseado na perspectiva discursiva - contrasta com o modo pelo qual os próprios professores concebem a docência. Para eles, preocupados em resolver os desafios da vida escolar cotidiana, o magistério revela-se mais como um "ofício" pautado por saberes práticos e questões de ordem ética, que orientam o seu discernimento para uma atuação pertinente em cada situação e em cada momento (Chartier, 1990; Rios, 1995; Aquino, 1998; Sarti, 2000).

A universidade apresenta aos professores práticas que alcançam alto valor simbólico, especialmente no próprio meio acadêmico, tais como o tratamento teórico das questões de ensino, o conhecimento do léxico acadêmico e a reflexão sobre o ensino a partir de pressupostos de natureza teórica. No entanto, a formação de professores mais competentes requer também uma exploração detida dos saberes pedagógicos que assumem maior "valor de uso" para o ensino.

Acredita-se, com Jean-Louis Derouet (2002) e também com Christiane Etévé e Patrick Rayou (2002), que os professores poderiam atribuir maior sentido aos saberes acadêmico-educacionais - e, portanto, aos textos que os fazem circular -, se eles passassem por processos de "reproblematização", ou seja, por desconstruções e reconstruções parciais, orientadas pelas necessidades e pelos valores próprios à instituição escolar e ao trabalho docente. Esses 
saberes não seriam, portanto, meramente "transferidos" (como se somente a universidade produzisse saberes) ou "traduzidos" (como se sua pertinência não dependesse do contexto em que são produzidos e empregados na passagem de um campo a outro, como sugere o conceito de transposição didática'! .

Etévé e Rayou (2002) esclarecem que a noção de "reproblematização" possibilita apreender com maior acuidade a circulação de saberes acadêmicoeducacionais, por evidenciar as continuidades e as rupturas que se estabelecem entre o trabalho de pesquisadores vinculados às Ciências da Educação e a docência realizada cotidianamente pelos professores. Para esses pesquisadores franceses, a idéia mostra-se promissora para o estabelecimento de relações mais férteis entre o campo da produção acadêmica e a escola, sugerindo a produção de pesquisas para a educação e não somente sobre a educação. Destarte, muitos dos problemas vividos pela escola poderiam ser focalizados de modo mais adequado nas investigações (sem que estas tivessem a incumbência de indicar soluções imediatas); enquanto, de sua parte, os professores conheceriam mais detidamente as contribuições oferecidas pelas pesquisas, mesmo que não as empregassem diretamente em seu trabalho (Prost, apud Etévé, Rayou, 2002).

Esses propósitos incluem mudanças significativas para a formação dos professores e também para a produção de conhecimentos acadêmico-educacionais, que deixariam de limitar-se à busca de explicações abstratas sobre o ensino, para focalizar também "o jogo das complexas relações sociais que ocorrem no processo institucional da educação" (Azanha, 1995, p.7I). Esse caminho poderia, inclusive, evitar muitos dos desencontros que têm caracterizado as relações estabelecidas entre escola e universidade e, também, entre professores e pesquisadores. As escolas deixariam de figurar como meros objetos de estudo, como se queixam os professores, graças à abertura de espaços

II. O conceito de "transposição didática", formulado por Verret (1975) e rediscutido por Chevallard (1985), pressupõe a existência de especificidades na constituição dos saberes ensinados na escola, que os diferenciam dos saberes produzidos pelas ciências de referência. No entanto, de acordo com tal perspectiva, as transformações operadas nos saberes de referência correspondem a meras simplificações que, realizadas por profissionais externos à escola, têm em vista possibilitar seu ensino aos alunos. Essas idéias têm sido objeto de diversas críticas por parte de autores que, como Chervel (1990), chamam atenção para a existência de uma "cultura escolar", a partir da qual a escola se apropria, modifica e transmite os saberes. 
para a incorporação de conhecimentos que os docentes possuem sobre a instituição escolar. Ao mesmo tempo, os professores teriam acesso aos resultados das investigações e poderiam integrá-los aos seus saberes sobre a escola, como esperam os pesquisadores. Vislumbra-se, com isso, a "incorporação de novas políticas de pesquisa e novos modos de se conceber o conhecimento sobre o ensino" (Bueno, 1998, p.9).

Cabe reconhecer os esforços que já estão em curso a esse respeito. Muitas pesquisas acadêmicas realizadas nas últimas décadas têm escolhido a escola como objeto privilegiado de estudo, focalizando seus êxitos, práticas e dificuldades. Programas de formação e impressos atualmente dirigidos aos professores também procuram oferecer maior preparo para o conhecimento e o exercício da docência. O PEC-Formação Universitária parece, inclusive, ser um bom exemplo desse tipo de esforço, pois tinha entre suas propostas a de que os professores lessem textos sobre o trabalho docente e que dirigissem o olhar para as características e problemas da escola em que lecionavam.

No entanto, esse modo de conceber a aproximação entre a universidade e a escola resulta, muitas vezes, na imposição de modelos para a percepção das questões de ensino. Com isso, a escola passa a ser tomada sob o ponto de vista acadêmico, sem que os saberes dos professores sejam realmente considerados sob os critérios práticos que lhes são próprios. Atua-se na formação docente como se somente as universidades tivessem algo a dizer sobre a escola, já que várias delas vêm, de fato, produzindo saberes interessantes a esse respeito, e como se coubesse aos professores somente aprender esse modo específico de aproximar-se do ensino. Por meio dessa situação, o papel formador da universidade torna-se cada vez mais legítimo perante a sociedade, os próprios professores e o poder público, mas se perde a oportunidade de apreender indícios da cultura pedagógica que é compartilhada entre os docentes, fonte de conhecimentos mais pertinentes sobre a escola. Isso porque, "são eles, os professores, que têm acesso diário aos problemas da sala de aula e podem por isso discorrer sobre os mesmos com familiaridade; mais do que isto, são eles que de fato podem apostar na melhoria do ensino" (Bueno, 1998, p.9).

A desconsideração desse aspecto concorre para a pobreza hoje presente no cenário da formação do professor que, como alerta António Nóvoa (1999), tem movimentado um mercado bastante rentável para aqueles que dela se ocupam, embora, lamentavelmente, mostre-se carente de práticas mais efeti- 
Leituras profissionais docentes...

vas de reflexão sobre as experiências dos professores e de partilha de seus saberes profissionais.

Contudo, uma atuação mais coerente por parte da universidade na valorização do magistério requer que as intenções de mera universitarização da formação docente sejam suplantadas, de modo a levar em conta as diferenças culturais e de interesses que, embora muitas vezes anuviadas pela realidade educacional que se impõe, insurgem vigorosas no encontro do ambiente escolar com o universo acadêmico, configurando inclusive as maneiras pelas quais os professores se reapropriam das práticas e dos produtos investidos em sua formação. Segundo os dados aqui apresentados, os professores não se mostram passivos diante das tentativas que têm sido feitas para universitarizar seus saberes, valores, discursos e práticas, uma vez que seus pontos de vista sobre o ensino e a escola encontram lugar nas entrelinhas do discurso acadêmico, subvertem sua ordem e, graças a isso, seguem existindo. Algo que impõe dificuldades e limites para que a universidade alcance seu objetivo de transformar os professores em novos consumidores de seus discursos e produtos.

Esse cenário aponta para a necessidade de mudanças no que se refere aos modos pelos quais a universidade se apresenta aos professores e assume para si a sua formação. É desejável que a centralidade conferida atualmente aos modos acadêmicos de se relacionar com as práticas e os saberes pedagógicos seja alterada em direção a novas formas de negociação e comunicação com os professores, o que inclui, por exemplo, novos mecanismos de divulgação dos conhecimentos. Nessa perspectiva, algumas questões: como escrever para os professores? Que processos devem anteceder e acompanhar a divulgação desses conhecimentos para que eles possam ser reproblematizados em razão das especificidades da cultura docente, sem, no entanto, perder as suas principais características? Quais os veículos mais adequados para essa comunicação? Que valores a universidade e as agências financiadoras passarão a atribuir a esse tipo de produção?

Algumas mudanças já têm ocorrido no âmbito das produções acadêmicas nesse sentido. Tais alterações, no entanto, limitam-se a "facilitar" a leitura dos professores, considerando suas dificuldades - reais ou supostas - relacionadas à leitura, à compreensão dos textos e à relação com as produções acadêmicas. As apostilas produzidas para o PEC oferecem exemplos desses "facilitadores": destaque de palavras e conceitos-chave, biografia dos autores, 
explicações detalhadas sobre os assuntos tratados, sínteses e exercícios de caráter marcadamente diretivo, amplo emprego de cores na organização dos textos. Esses recursos associam-se a outras práticas utilizadas pelo programa também voltadas a "proteger" os professores contra eventuais dificuldades na realização das atividades de natureza acadêmica. Paradoxalmente, tais estratégias, empregadas em um programa de universitarização, acabam por caracterizar um processo de secundarização da formação ${ }^{12}$.

Diante desse quadro, algumas professoras mostravam-se descontentes e questionavam o status universitário da formação que recebiam no PEC. Também para as universidades envolvidas, esta era uma fonte de conflitos, já que implicava alterar práticas tradicionalmente relacionadas ao ambiente acadêmico, como a leitura de obras de referência, a pesquisa bibliográfica, a leitura intensiva e extensiva de livros e de outras publicações etc.

Cabe ressaltar, no entanto, que essa secundarização da formação dos professores encontra-se distante dos propósitos de reproblematização dos saberes acadêmicos, no sentido apresentado. Alheio à perspectiva dos professores sobre os temas educacionais, esse processo atua como mais um dispositivo que a universidade tem empregado para impor seus discursos sobre a escola, o ensino, os alunos e os professores.

Seguindo o caminho proposto por Certeau (1994, p.49), é possível antever que mudanças de outra natureza decerto ocorrerão no campo da produção de textos acadêmico-educacionais, mesmo que à revelia dos pesquisadores. Isso porque os próprios professores, com seus modos específicos de ler e suas astúcias de consumidores, produzem silenciosamente "novos textos", com base naqueles mesmos textos que, reinventados pela universidade secundarizados - buscam conformar sua leitura. Assim, por meio dessa "dança efêmera" que não se capitaliza, os professores provocam mudanças - mesmo que lentas e pouco visíveis - no cenário de produção e circulação de textos no campo educacional.

Uma compreensão mais abrangente da universitarização da formação dos professores ora em curso requer, de um lado, uma apreensão das maneiras

12. Pode ser entendido em duplo sentido: como práticas típicas da educação secundária e como algo que é simbolicamente secundário na hierarquia dos valores sociais. 
Leituras profissionais docentes...

pelas quais os professores se defrontam com as estratégias empregadas nesse processo, como delas se apropriam e que lugares assumem nesse contexto, como dito de início; e, de outro, a compreensão dos efeitos e possibilidades que essa "atividade de formigas" (Certeau, 1994, p.40) empreendida por eles traz para a vida na universidade, vale dizer, para as práticas, discursos e valores acadêmicos.

\section{REFERÊNCIAS BIBLIOGRÁFICAS}

AQUINO, J. G. Ética na escola: a diferença que faz a diferença. In: AQUINO, J. G. (org.). Diferença e preconceito na escola: alternativas teóricas e práticas. São Paulo, Summus, 1998. p.|35-|5|.

AZANHA, J. M. P. Educação: temas polêmicos. São Paulo: Martins Fontes, 1995.

BOUDON, R. Effets pervers et ordre social. Paris: PUF, 1977.

. Le Sens des valeurs. Paris: Quadrige, PUF, 1999.

BOURDIEU, P. La Domination masculine. Paris: Seuil, 1998.

. A Economia das trocas lingüísticas: o que falar quer dizer. São Paulo: Edusp, 1996. [ Trad.: Sérgio Miceli et al.]

Gostos de classe e estilos de vida. In: ORTIZ, R. (org.). Pierre Bourdieu. São Paulo: Ática, 1983. p.82-121.

BOURDONCLE, R. Normalisation, académisation, universitarisation, partenariat: de la diversité de voies vers l'université. Revista da Faculdade de Educação, v.23, n. I/2, p. 29-48, jan./dez. 1997.

. Professionnalisation, formes et dispositifs. Recherche et Formation, n.35, p. I17-132, 2000.

BRASIL. Ministério da Educação e Cultura.Lei de Diretrizes e Bases da Educação Nacional. Brasília, 1996.

BRASIL. Ministério da Educação. Instituto Nacional de Estudos e Pesquisas Pedagógicas. Estatísticas dos professores no Brasil. Brasília, 2003.

BUENO, B. O. Autobiografia e formação de professores: um estudo sobre representações de alunas de um curso de magistério. São Paulo, 1996. Tese (livre doc.) Faculdade de Educação, Universidade de São Paulo. 
BUENO, B. O. Educação a distância: entre o presencial e o virtual; a formação, a leitura e a escrita dos professores. São Paulo, 2003. mimeo. [Projeto Integrado/CNPq]

É possível reinventar os professores? A "escrita de memórias" em um curso especia/de formação de professores. In: SOUZA, E.; ABRAÃO, M. H. Tempos, narrativas e fiç̧ões: a invenção de si. Porto Alegre: EDIPUCRS, 2006. p.219-238.

. Pesquisa em colaboração na formação contínua de professores. In: BUENO, B.; CATANI, D. B.; SOUSA, C. (orgs.) A Vida e o ofício dos professores. São Paulo: Escrituras, 1998. p.7-20.

CERTEAU, M. de. A Invenção do cotidiano: artes de fazer. Petrópolis: Vozes, 1994.

CHARTIER, A.-M. Culture scolaire et savoirs : approche historique. Ville-École-Intégration Enjeux., n. I33, p. 192-2 15, juin 2003. [Culture(s): entre fragmentation et recompositions]

En quoi instruire est un métier. In: COLLOQUE DE LA ROCHELLE: Le Métier d'instruire. Actas... Collége International de Philosophie, I5-16 mai 1990. p.21-38.

Expertise enseignante entre savoirs pratiques et savoirs théoriques. Recherche et Formation, n.27, p. 67-82, 1998.

. Os Futuros professores e a leitura. In: BATISTA, A.; GALVÃO, A. M. (orgs.) Leitura: práticas, impressos, letramentos. Belo Horizonte: Autêntica, 1999. p.89-97.

CHARTIER, R. A História cultural: entre práticas e representações. Lisboa: Difel, 1988.

- A Ordem dos livros: leitores, autores e bibliotecas na Europa entre os séculos XIV e XVIII. Brasília: UnB, 1999.

CHERVEL, A. História das disciplinas escolares: reflexões sobre um campo de pesquisa. Teoria e Educação, Porto Alegre, n.2, p. 177-229, 1990.

CHEVALLARD, Y. La Transposition didactique: du savoir savant au savoir enseigné. Grenoble: La Pensée Sauvage, 1985.

DEROUET, J.-L. Du transfert à la circulation des savoirs et à la reproblématisation: de la circulation des savoirs à la constitution d'un forum hybride et de pôles de compétences: un itinéraire de recherche. Recherche et Formation, n.40, p. 13-25, 2002.

ELIAS, M. D. C. De Emílio a Emília: a trajetória da alfabetização. São Paulo: Scipione, 2000.

ETÉVÉ, C.; RAYOU, P. Le Demande de transfert des résultats de la recherche. Recherche et Formation, n.40, p.27-4I, 2002.

FISH, S. Is there a text in the class? Cambridge: University of Harvard, 1982. 
Leituras profissionais docentes...

FOUCAULT, M. Dits et ecrits II: 1976- 1979. Paris: Gallimard, 1994.

KLEIMAN, Â. B. (org.) A Formação do professor. perspectivas da lingüística aplicada. Campinas: Mercado de Letras, $200 \mathrm{I}$.

NÓVOA, A.. Os Professores na virada do milênio: do excesso dos discursos à pobreza das práticas. Educação e Pesquisa, São Paulo, v.25, n. I , p. I I-20, jan./jun. 1999.

PERRENOUD, P. Práticas pedagógicas, profissão docente e formação: perspectivas sociológicas. Lisboa: Instituto de Inovação Educacional, 1993.

RIOS, T. A. Ética e competência. 7. ed. São Paulo: Cortez, 1995. (Questões de Nossa Época, 16)

SANTOS, E. P. dos. Professoras em tempos de mudança: trabalho docente na rede pública de educação do estado de São Paulo (1960-1980). São Paulo, 2003. Dissert. (mestr.) Faculdade de Educação, Universidade de São Paulo.

SÃO PAULO (Estado). Secretaria de Educação. PEC-formação universitária: apostilas. São Paulo, 2001.

SARTI, F. M. Leitura profissional docente em tempos de universitarização do magistério das séries iniciais. São Paulo, 2005. Tese (dout.) Faculdade de Educação, Universidade de São Paulo.

Mestres-de-ensino: um estudo etnográfico sobre a dimensão ética do ofício de formar professores. São Paulo, 2000. Dissert. (mestr.) Faculdade de Educação, Universidade de São Paulo.

SARTI, F. M.; BUENO, B. O. Leitura profissional docente e os limites da universitazação do magistério. In: REUNIÃO ANUAL DA ANPED, 29. Anais... Caxambu, 2006.

Teachers as 'new readers' of educational academic texts. In: THE INTERNATIONAL STANDING CONFERENCE FOR THE HISTORY OF EDUCATION, 28. Umea, Suécia, 2006a. mimeo

SCHEFFLER, I. A Linguagem da educação. São Paulo: Edusp; Saraiva, 1974.

VERRET, M. Les Temps de études, 2. Paris: Honoré Champion, 1975.

VIEIRA, D. A. História do magistério: experiências masculinas na carreira administrativa no estado de São Paulo (1950-1980). São Paulo, 2002. Dissert. (mestr.) Faculdade de Educação, Universidade de São Paulo.

Recebido em: janeiro 2006

Aprovado para publicação em: dezembro 2006 